Luis-Alberto Sanchez

\title{
Sobre las letras peruanas en los últimos diez años
}

una literatura libre, honda ni pura. Aunque los escrito-
res se preocupen con mayor ahinco de su instrumento
dumbres colectivas, una de ellas, el cerrado horizonte que les cerca
con su consiguiente cortejo de limitaciones. La creación artística re-
quiere siempre libertad: externa e interna, o, al menos, la última.
Caso, éste, en que el escritor posee una dosis de heroísmo intelectual,
de capacidad de abstracción incalculable.
Entre 1945 y 1955, el ambiente literario del Perú se ha visto
solicitado por singulares alicientes, en especial, un ansia de ecume-
nismo en la forma, por desgracia atemperada por una insistente vo-
luntad de permanecer atado a temas locales, no tan significativos co-
mo se quisiera. El duelo implícito entre universalidad y criollidad se
resuelve de modo diferente según el grado de autonomía de que dis-
pongan los individuos. Por lo común, bajo el peso de imperiosos dic-
tados, el debate se inclina a lo más fácil: al nacionalismo, aunque sea
de discutible calado.

Ocurre, además, otra circunstancia extendida a todo el continente: la creciente corrección de la forma no está acompañada de pa- 
reja elevación de los temas ni de las individualidades. En otras palabras: cada día hay menos malos escritores, sobre todo menos malos versificadores, pero cada día hay menos grandes escritores, en especial, grandes poetas. Una especie de medianización por lo alto alivia al lector común, pero no al creador.

De los géneros literarios, sin duda la poesía es la que más ha sufrido a consecuencia de tal impacto. La novela y el cuento se libran a medias, por la cantidad de temas inéditos de que disponen. Eso les permite mantener cierto señorío, aunque no despeguen el vuelo del relato, gloria y maldición de las narraciones americanas.

Antes de 1945, se habían consagrado en la novela dos autores: Ciro Alegría y José María Arguedas. En 1955 siguen siendo los más calificados, a pesar de no haber producido obra novelesca de valfa (si alguna) en el lapso de este decenio. No obstante cabe sentirse optimista. No tanto por la consagración de un relatista adulto, Francisco Vegas Seminario, con Montonera (1955), inferior a su libro de narraciones, de 1946, cuanto por la aparición de un grupo de cuentistas jóvenes, obedientes a diversas consignas: los unos, a decantar el análisis de las pasiones; los otros, a pintar exteriores vernáculos.

A la primera de estas vertientes pertenecen, según recuerdo, C. E. Zavaleta, La batalla; C. Congrains, Lima, hora cero; Julio Ribeyro, Manuel Mejía Valer; a la segunda, también los dos primeros, pero sobre todo Porfirio Meneses, V. Peláez, y tal vez, alguien a quien no recuerde.

Zavaleta, aunque muy joven, tiene ya una larga foja de servicios literarios. En 1948 venció en un concurso de cuentos, organizado por la Universidad de San Marcos. Su estilo se pliega a menudo al de los cuentistas norteamericanos, en especial, a Faulkner, de quien ha recibido lecciones de penetración y divagación, parejamente. Congrains maneja un sobrio estilo narrativo. Sin alardes doctrinales, encara aspectos amargos y olvidados de la vida diaria. Acomete así una forma que podría calificarse de social, si este adjetivo no estuviera demasiado cargado de sentido partidario. Ribeyro cultiva un cuento más libre de influencias inmediatas. Joven también, tal vez no tanto 
como Congrains, se encuentra en Europa, absorbiendo lecciones de literatura francesa y alemana. Mejía Valer, otro joven escritor, ha publicado un cuaderno de cuentos en México. Se advierte en ellos un prurito acaso excesivo de limpieza verbal que puede llegar $-y$ a ratos llega - al amaneramiento. La atmásfera del Colegio de México y su niebla filológica se adhiere en demasía a sucesos tan humanos como los que constituyen la temática de Mejía.

Frente a este grupo, podría señalarse otro, en el que, ocasional y tangencialmente militaría Vegas Seminario: el de los vernaculistas. Entre ellos hay dos estupendos narradores: Peláez Bazán y Porfirio Meneses. Pertenecen a una estirpe mesticista, recia, dramática, llena de vigor, a menudo folklórica. Pero a diferencia de los personajes y asuntos de Ventura García Calderón (muy forzados) y de López Albújar (harto rapsódicos), los de Meneses y Peláez no pierden en ningún instante su contenido $\mathrm{y}$ fondo literario.

Dos relatistas costeños: José Diez Canseco (fallecido en 1949, a los 44 años) y Fernando Romero (dedicado a labores burocrático-didácticas en Washington D.C.) contribuyen al desarrollo del relato peruano en esta década. Ambos criollistas. El primero, de una prosa irónica, frecuentemente poética, pudo ser el representativo de la novela criolla.

En el verso (dejemos la palabra poesía por el momento) mantienen su señorío poetas anteriores a la década que nos ocupa. Sin duda, Travesía de Extramares, de Martín Adán, publicado en 1951, y un poemario de Alberto Escobar; el retorno a la poesía de Luis Valle Goicochea; la antología de Mario Florián, ya premiado en 1945; el fugaz destello de Gustavo Valcárcel; la eclosión de Alejandro Romualdo; la reaparición triunfante de Julio Garrido Malaver (vencedor de un concurso poético en 1940); la lealtad expresiva de Sebastián Salazar Bondy y Gonzalo Ross - son otros tantos hechos, entre los que recuerdo, dignos de examen y reflexión. Si Francisco Bendezú, uno de los benjamines literarios, hubiese dado ya a la estampa su Antología, y si Juan Ríos (fino espíritu y grande inquietud) hubiese mantenido su fidelidad a la poesía, en vez de dedicarla 
al teatro, creo (y perdóneseme mis olvidos e ignorancias) que tendríamos un cuadro más cabal de este corto lapso literario. Repito: de lejos no es posible ser del todo exacto; además, no quiero ser de ninguna manera colector de cuantías, sino cosechador de excelencias.

Martín Adán (mayor de 45 años ahora) es un caso impar. Su prosa surrealista inauguró con La casa de cartón, en 1928, una nueva aventura literaria en el Perú. Clásico de raíz, cultivaba sonetos y romances de compacto atavío y peligrosa intención. Los Antisonetos, popularizados en Amauta labraron su fama poética. La vida derivó después cruelmente. La imaginación se convirtió en cilicio. Rafael de la Fuente ha tejido en el entretanto, con virtuosismo morboso, los versos de Travesía de extramares, cuya belleza corre a la par de su exotismo y estrambotismo, cuya hambre de melodía echa a correr por las rutas de la ecolalia, salpicada de ocasionales y magníficas metáforas. Martín Adán no deja escuela, pero enseña a decantar y depurar.

Las analogías con Lautreamont, usadas a propósito de Martín, carecen de fundamento. Lo exótico en Lafuente viene de adentro, fruto de proceso orgánico, propio, sin concesiones imitativas. Imposible imitarle. Además, inconveniente.

Podría colocarse en sitiales casi antagónicos a éste de Martín Adán, a Mario Florián y a Julio Garrido Malaver. El primero empezó con una poesía nativista, pero, a diferencia del folklorismo rimado, que algunos le atribuyen, tuvo más bien un sentido poético de lo vernacular. La poesía indigenista peruana osciló por lo general entre la ramplonería descriptiva y la ramplonería protestadora o pseudo-revolucionaria. Las excepciones son pocas y ocasionales: González Prada, ciertos poemas de José Varallanos y de Alejandro Peralta, pero los últimos con innegable retórica vanguardizante. Florián, como García Lorca (símil audaz, pero espontáneo), poetiza lo consuetudinario. No deliberadamente: por mandato de su ser y de las cosas. Garrido posee un aliento más trascendental y tierno. Hay en su canto notas patéticas, severamente sofrenadas por una orgullosa humildad de viviente a plenitud. En sus labios las palabras dolor, 
amor, angustia, no suenan a falso. Traducen una realidad. Vienen de adentro. Si flotan, espuma son de una amarga y terrible tempestad. No es que exalte una poesía de anécdota, en tono neorromántico. No. Pero, creo, con Rilke, en la poesía de maduración, de vital mensaje. De ahí, que los finos y brillantes versos de otros poetas, sabedores sutiles de su arte, me conmuevan menos. Advierto en Escobar a un experto decantador de emociones; en Romualdo, una fuerza imaginativa, un impulso cada vez más depurado y poderoso aún en marcha o proceso de cristalización; en Salazar, elegancia y concepto; en Eielson, ingenio y fantasía. Aparte, Juan Ríos yergue su figura concentrada, solitaria, de una voz singular, voz a la que no son ajenas la protesta ni la queja; vida en que no disuenan el amor ni la revolución, y, además, sabiamente entrenado en disciplinas retóricas del día.

Se bosquejan otros poetas: Manuel Scorza, quien ha dado un puñado de notas líricas, promisorias, no cuajadas aún; Luis Carnero Checa, elocuente y enumerativo; todos ellos esforzados por hallar la ecuación entre la angustia personal y la inquietud colectiva, a través de modos generalmente nerudianos, influencia persistente en excesiva parte de la actual poesía americana.

Del ensayo, habría poco que decir. Se conserva la rectoría de Antenor Orrego, laborioso, original y brillante. No ha publicado libro en esta etapa, pero sus trabajos en revistas como Cuadernos (Perú), Cuadernos americanos (México), Humanismo (México), etc., son bastantes para ratificar su prestigio. Orrego prepara un libro sobre Vallejo, a quien él anunció y prologó desde 1917 y 1922, respectivamente.

Vallejo, pues incidimos en él, constituye la otra gran influencia que, junto a la de Neruda, envuelve a la mayor parte de la poesía peruana de esta década. Recuerdo aquí lo que Dámaso Alonso me decía en Madrid, en febrero de este 1956: "La sombra de Vallejo crece, en vez de declinar; tiene porvenir después de muerto. Convendría analizar este hecho. No sólo por sus formas, sino por sus raíces y resonancias".

Dos son las mayores influencias que pesan sobre la poesía peruana de hoy: Eguren y Vallejo, dentro de lo nacional, y Neruda, dentro 
de lo foráneo. El impacto de García Lorca se ha debilitado. La crítica vuelve a rexaminar a Chocano, de quien se extraen inesperadas lecciones, sobre todo ahora que se han publicado sus Obras completas. Eguren representa lo alado, grácil, intrascendente, estéticamente pueril; Vallejo, lo terrestre, patético, grávido de ideas y sensaciones humanas, adulto. Los dos, inimitables. Esa es su gloria y su tropiezo. $\mathrm{Ni}$ Eguren ni Vallejo admiten discípulos: secuaces o admiradores, sí. De ahí que la poesía peruana actual se encuentre un tanto desguarnecida de los necesarios tutores inmediatos. La presencia de Neruda, otro impar, pero de una retórica contagiosa y visible, no atenúa ni mucho menos elimina el problema.

Los ensayistas se dan cuenta de ello y lo subrayan, aunque, acaso, poniendo demasiado énfasis en el aspecto local o terrígeno de dichos poetas. Así Jiménez Borja nos habla del valor geográfico de Eguren; Elsa Villanueva, Antenor Samaniego y el francés Croydon insisten en ciertos aspectos folklóricos de Vallejo. Orrego, en eso, con pleno y primordial conocimiento de personaje y tema, continúa alumbrando la cuestión. Se explica: Orrego es el más audaz y universalista (americanista con vistas ecuménicas) de los ensayistas peruanos en vigencia.

Han surgido otros nombres, con obras aisladas, algunas de ellas significativas, $y$, se han repetido otros nombres, de prestancia anterior: Luis Valcárcel, Honorio Delgado, Raúl Porras, Jorge Basadre, Alberto Wagner, Antenor Samaniego, Luis, F. Alarcón, Andrés Townsend, F. Miró Quesada. En el periodismo de ideas, la tarea reemprendida por Haya de la Torre ( a través de Bohemia de La Habana; Universal, de México; Acción, de Montevideo; Ibérica, de Nueva York; Cuadernos Americanos, de México, etc.), reúne los requisitos de un vasto e ininterrumpido ensayo-mensaje y de una sostenida prosa periodística. Algo nos corresponde personalmente en este cuadro, a través de libros y artículos. Javier Pulgar Vidal ha ilustrado la prosa científica con magníficos trabajos de investigación y divulgación. Pero, en todo nsto se revela a primera vista una división fundamental: la producción casera y la peregrina. Aquélla más historicista; ésta más ideológica; con menos libertad allá, con casi toda aquí. Dentro de las fronteras perua- 
nas; estos últimos ocho años han significado la amputación de importantes temas e ideales. Si ello condice con alguna perfección formal y remozado rigor científico, sería menos malo. Si no, habrá que lamentar la renovada paralización de una cultura alimentada por siglos de buen gusto e inquietud, deformada por lustros de impuesta ramplonería y obligada sordina.

El que, en medio de tan contradictorias circunstancias exteriores, siga floreciendo el relato, se mantenga la poesía, crezca la novela y sobreviva el ensayo, habla muy alto de las capacidades y posibilidades de la nueva generación peruana. 